\title{
Study of endothelial function in pregnant women with gestational diabetes mellitus by flow mediated dilation of brachial artery
}

\author{
Nidhi Pandey ${ }^{1 *}$, Poonam Goel ${ }^{1}$, Anita Malhotra ${ }^{2}$, Reeti Mehra ${ }^{1}$, Navjot Kaur ${ }^{1}$
}

\begin{abstract}
${ }^{1}$ Department of Obstetrics and Gynecology, Government Medical College and Hospital, Chandigarh, India
${ }^{2}$ Department of Physiology, Government Medical College and Hospital, Chandigarh, India
\end{abstract}

Received: 09 April 2020

Accepted: 01 May 2020

*Correspondence:

Dr. Nidhi Pandey,

E-mail: nidhipandey74@gmail.com

Copyright: (c) the author(s), publisher and licensee Medip Academy. This is an open-access article distributed under the terms of the Creative Commons Attribution Non-Commercial License, which permits unrestricted non-commercial use, distribution, and reproduction in any medium, provided the original work is properly cited.

\begin{abstract}
Background: The objective of the study was to assess vascular function in normal pregnant women and women with gestational diabetes and to study its temporal relationship with gestational age at 24-28-week POG and at 36-38-week POG and changes in FMD in postpartum period.

Methods: Assessment of vascular function was done at 24-28-week POG, 36-38-week POG and at 6-12-week postpartum by flow mediated dilation of brachial artery in 37 healthy pregnant women and 37 pregnant women with GDM.

Results: In GDM group mean FMD at 24-28 weeks of POG, at 36-38 weeks POG was lower as compared to the control group $(11.225 \pm 6.20,8.464 \pm 6.09$ versus $14.49 \pm 5.21,10.898 \pm 4.12)$ although the difference in mean FMD in two groups was not statistically significant. It was found that the decrease in FMD at 36-38-week POG as compared to 24-28 weeks POG was statistically significant in both the groups $(\mathrm{p}<0.001)$.

Conclusions: This study revealed that when endothelial function as assessed by FMD was compared at different period of gestation, the mean decrease in FMD at 36-38-week POG as compared to 24-28-week POG and 6-week post-partum was statistically significant in patients with GDM and as well as the control group, however this trend of change was same in both the groups and was not statistically significant when compared between the two group (GDM versus control). A negative correlation of FMD was found with BMI, and HBA1c, that was stronger in GDM group.
\end{abstract}

Keywords: Brachial artery, Endothelial function, Flow mediated dilation, Gestational diabetes mellitus, Impaired glucose tolerance, Period of gestation

\section{INTRODUCTION}

Gestational diabetes mellitus (GDM) is defined as a state of carbohydrate intolerance detected for the first-time during pregnancy and its prevalence rate varies between $1-14 \%$ globally and $12-21 \%$ in Indian women. ${ }^{1-3}$ GDM is associated with not only adverse maternal (preeclampsia, stillbirths, macrosomia, and need for caesarean section etc.) and neonatal outcomes (hypoglycaemia, respiratory distress etc.), but also with increased risk of late complications in mother as well as in the baby. ${ }^{4}$ On longterm it is associated with diabetes mellitus as well as increased cardiovascular disease. The incidence of type 2 DM has been shown to be 7.5 times. $^{5}$

Despite their relative youth (i.e. their child bearing age) women with GDM have a 70\% higher incidence of cardiovascular event as compared to their peers, within just 11 years following the index pregnancy.

It has been proposed that high cardiovascular risk seen in these patients could be because of underlying vascular dysfunction. ${ }^{6-11}$ The main reason for alteration in vascular function is because of association of GDM with 
endothelial dysfunction and increased inflammatory markers.

The endothelial dysfunction occurring because of hyperglycaemia in GDM patients is probably mediated through factors such as the activation of protein kinase $\mathrm{C}$, increased activity of the polyol pathway, non-enzymatic glycation and oxidative stress. ${ }^{12}$

Flow-mediated dilation (FMD) is a safe and simple technique during pregnancy, which has been widely used to assess endothelial dysfunction. It involves imaging of a brachial artery by Doppler ultrasound before and after a period of ischemia and noting the changes in relation to dilatation because of ischemia. An attenuated FMD response signifies endothelial dysfunction which may result in increased cardiovascular risk. ${ }^{13-15}$

Most of the studies to evaluate endothelial dysfunction as assessed by FMD in GDM have been conducted in postpartum period and very few have been done during pregnancy, hence a study was planned to evaluate endothelial function, as assessed by flow-mediated dilation of brachial artery in pregnant women with gestational diabetes mellitus.

\section{METHODS}

It was a prospective cohort study comprising of two groups of pregnant females: one with gestational diabetes mellitus (diagnosed at 24-28 weeks POG) and other group consisting of healthy pregnant females.

A total of 74 patients (based on sample size estimation) were recruited from the outpatient department of obstetrics and gynecology. There were 37 pregnant women with GDM and 37 pregnant healthy females. After taking an informed consent, a detailed obstetric and medical history was taken and general physical examination and per abdomen examination was done.

Patient diagnosed as GDM were put on MNT (medical nutritional therapy) and oral hypoglycemic agents (OHA) or insulin along with the standard protocol of management of GDM. FMD was measured at the time of recruitment of patient i.e. around 24-28 weeks POG of gestation, then at around 36-38-week POG and at 6-12 weeks postpartum. Patients were followed up and aternal and fetal outcome were recorded. For determination of FMD the method devised by Celerrmajer was used and latest guidelines of the Brachial Artery Reactivity Task Force was followed. ${ }^{16,17}$

\section{Inclusion criteria}

- Gestational diabetes.

\section{Exclusion criteria}

- $\quad$ Pre- pregnancy diabetes
- Severe anemia

- Hypertension

- Renal, liver hematological disorder

- Twins pregnancy

- Smoking

- Autoimmune disorders

- Vascular disorders.

\section{Vascular function assessment}

FMD was assessed in all recruited patients using highresolution ultrasound system (AUSCON X 300 premium edition) having vascular software for a high frequency linear array probe (7-12 MHz) or two-dimensional (2D) imaging. A sphygno-manometric cuff was placed after localizing the brachial artery above the antecubital fossa in longitudinal plane on USG Doppler. Cuff inflated to supra-systolic pressure of $50 \mathrm{mmHg}$ for 5 minutes so as to create arterial occlusion leading to reactive hyperaemia in brachial artery. Subsequently brachial artery images were continuously recorded for 30 seconds and 2 minutes after the cuff was deflated by US. The maximal brachial artery diameter after 60 seconds of reactive hyperaemia was compared to the baseline vessel diameter and the difference was defined as the difference in percent flowmediated dilation (\%FMD).

\section{Statistical analysis}

Continuous data was expressed as mean (SD) with $95 \%$ confidence interval (CI) and qualitative data as proportions. Using unpaired t-test/Mann Whitney Test did a comparison of FMD between diabetics and healthy pregnant female at the baseline. The serial comparison of FMD values at different time points was done using paired. t-test/ Wilcoxon signed rank test. The correlation of blood glucose with FMD was done using persons correlation coefficient. Data analysis was done using SPSS version 22.0.

\section{RESULTS}

The mean age in Group A and Group B was 29.41 \pm 3.76 years and $28.86 \pm 4.668$ years respectively and the difference in age was statistically not significant $(\mathrm{p}<0.58)$ (Table 1). Mean BMI in pregnant female with GDM was $26.69 \pm 2.85 \mathrm{~kg} / \mathrm{m}^{2}$ and in control group it was $23.470 \pm 3.08 \mathrm{~kg} / \mathrm{m}^{2}$ and the difference between the group was statistically highly significant $(p<0.001)$ (Table 1$)$.

The mean FMD in cases group (GDM patients) was lower as compared to controls (normal pregnancy) at both the gestation and in the post-partum period although the difference was not statistically significant (Table 2).

FMD was compared at 24-28 weeks POG, 36-38 weeks POG and 6-12 weeks postpartum within the group, and it was found that the decrease in FMD at 36-38 weeks POG as compared to $24-28$ weeks POG and 6-12 weeks post- 
partum was statistically significant $(\mathrm{p}<0.001)$ in both the groups, however this trend of change was same in both the groups and was not statistically significant when compared between the group (Figure 1).

Table 1: Comparison of maternal characteristics in GDM and normal pregnancy.

\begin{tabular}{|lll|}
\hline \multicolumn{3}{|l|}{ Maternal characteristics in the gestational diabetes mellitus (GDM) and normal pregnancy (NP) groups. } \\
\hline Maternal characteristics & Gestational diabetes mellitus (GDM) & Normal pregnancy (NP) \\
\hline Mean age in years & $29.41 \pm 3.76$ & $28.86 \pm 4.66^{*}$ \\
\hline BMI at inclusion in $\mathrm{kg} / \mathrm{m}^{2}$ & $26.69 \pm 2.85$ & $23 \pm 3.08^{* *}$ \\
\hline Parity & & 12 \\
\hline Nulligravida (n) & 11 & 25 \\
\hline Multigravida (n) & 26 & $2.71 \pm 0.3921^{* *}$ \\
\hline Birth weight in $\mathrm{kg}$ & $3.06 \pm 0.4678$ & \\
\hline
\end{tabular}

Data are expressed as mean \pm SD. $* \mathrm{p}<0.05 ; * * \mathrm{p}<0.001$.

Table 2: Comparison of FMD at 24-28 weeks at 36-38 weeks and 6-12 weeks postpartum and correlation of FMD with degree of hyperglycaemia at 24-28 weeks and at 36-38 weeks POG.

\begin{tabular}{|lll|}
\hline FMID & $\begin{array}{l}\text { GDM } \\
\text { group }\end{array}$ & $\begin{array}{l}\text { Normal } \\
\text { pregnancy }\end{array}$ \\
\hline $\begin{array}{l}\text { Mean FMD at 24-28- } \\
\text { week POG }\end{array}$ & $11.22 \pm 6.20$ & $14.49 \pm 5.21$ \\
\hline $\begin{array}{l}\text { Mean FMD at 36-38- } \\
\text { week POG }\end{array}$ & $8.46 \pm 6.09$ & $10.89 \pm 4.17$ \\
\hline $\begin{array}{l}\text { Mean FMD at 6-12-week } \\
\text { post-partum }\end{array}$ & $12.14 \pm 6.35$ & $15.74 \pm 4.42$ \\
\hline
\end{tabular}

At $6-12$ weeks post-partum the value of mean FMD was almost reverted back to $24-28$ weeks POG value and this reversal in the value of FMD was less in GDM group as compared to control group but this difference was statistically non-significant (Figure 1).

There was a negative correlation of FMD with BMI in both the groups (case and control), but the difference was statistically not significant, however in case group the negative correlation was stronger as compared to control group (Table 3).

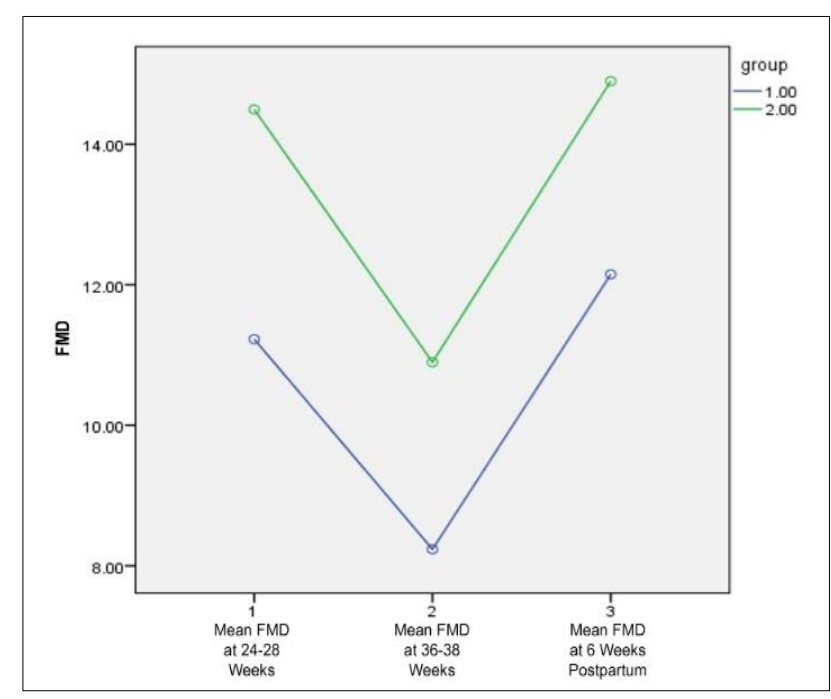

Figure 1: Comparison of mean FMD in Group A and Group B at 24-28 weeks POG, 36-38 weeks POG, 6 weeks postpartum.

Table 3: Correlation of FMD with HbA1c and BMI at 24-28 weeks POG and at 34-36 weeks POG and correlation of FMD with degree of hyperglycaemia.

\begin{tabular}{|lllll|}
\hline Parameters & \multicolumn{3}{c|}{ GDM Pr } & \multicolumn{2}{c|}{ Normal pregnancy P r } \\
\hline Correlation of HbA1c with FMD & & & & -0.15 \\
\hline At 24-28 weeks POG & $<0.11$ & -0.26 & $<0.37$ & -0.11 \\
\hline At 36-38 weeks POG & $<0.02$ & -0.36 & $<0.50$ & -0.05 \\
\hline Correlation of BMI with FMD & & & & -0.08 \\
\hline At 24-28 weeks POG & $<0.96$ & -0.007 & $<0.73$ & - \\
\hline At 36-38 weeks POG & $<0.31$ & -0.17 & $<0.6$ & - \\
\hline Correlation of FMD with blood sugars values of OGTT at 75 g of glucose & $<0.62$ & -0.08 & - & - \\
\hline Fasting blood sugar & $<0.44$ & -0.13 & - & - \\
\hline Blood sugar at 1 hour & $<0.19$ & -0.23 & - & \\
\hline Blood sugar at 2 hours & & & & \\
\hline
\end{tabular}


FMD had a negative correlation with HBA1c levels in both groups cases and controls. The negative correlation of HbA1c in Group A at 36-38 weeks POG was statistically significant as compared to 24-28 weeks POG (Table 3).

FMD at 24-28 weeks POG had a weak negative correlation with blood sugar values of OGTT at fasting, 1 hour and 2 hour and the difference was statistically not significant. There was a stronger negative correlation of FMD with blood sugar values at 2 hours of OGTT as compared to FBS and 1 hour (Table 3 ).

\section{DISCUSSION}

Gestational diabetes mellitus, is defined as glucose intolerance with onset or first recognition during pregnancy. Although GDM usually resolves postpartum, but women with GDM have an increased risk for the subsequent development of type 2 diabetes mellitus and also an increased risk of developing cardiovascular disease.

Endothelial dysfunction is the alteration in vessel response to defined stimuli associated with impaired relaxation, resistance and blood flow. Insulin resistance, hyperglycemia and low grade of systemic inflammation has been suggested as main mechanism for endothelial dysfunction in diabetic patients.

The effects of endothelial dysfunction can be measured by various techniques and may be quantified at both a macro vascular level and micro vascular level. ${ }^{18}$ In this study we used FMD as a measure of endothelial dysfunction in patients with GDM as compared to healthy pregnant women. An attenuated FMD response is associated with several conventional cardiovascular risk factors and currently is considered prognostic of increased cardiovascular risk. ${ }^{12,13}$

In GDM group mean FMD at 24-28 weeks of POG, at 36-38 weeks POG was lower as compared to the control group (11.225 $\pm 6.20,8.464 \pm 6.09$ versus 14.49 \pm 5.21 , $10.898 \pm 4.12$ ) although the difference in mean FMD in two groups was not statistically significant. Garg et al, measured FMD in $20 \mathrm{GDM}$ patient and compared with 20 healthy age matched pregnant women at 20-22+6 weeks+days and 30-32+6weeks+days and this study concluded that women with GDM had lower FMD in the third trimester compared to the second trimester (6.77 versus 7.78) but the difference was non-significant). ${ }^{19}$

Paradisi et al, reported that FMD at third trimester was significantly reduced in women with GDM when compared with controls (mean FMD of $4.1 \%$ in GDM vs. $10.9 \%$ in controls). ${ }^{20}$

Guimaraes DR et al, also reported a similar decrease in mean FMD in the third trimester in patients with GDM as compared to the controls $\left(9.18 \%, 17.55 \%\right.$ respectively). ${ }^{21}$
When mean FMD was compared at 24-28 week POG, 3638 weeks POG and 6-12 weeks post-partum in GDM patient and control group in our study it was found that the decrease in FMD at 36-38 weeks POG as compared to 24-28 weeks POG was statistically significant in both the groups $(\mathrm{p}<0.001)$, however this trend of change was similar in both the groups and was not statistically significant when compared between the two groups. In a recent study done by Malhotra AS et al serial assessment of endothelial function during pregnancy, using FMD for prediction of preeclampsia.

It was observed that there was a significant fall of FMD in all pregnant females at 32-34 weeks of POG. ${ }^{22}$

In this study it was observed that BMI had a negative correlation with FMD in GDM and control group. The correlation of FMD with BMI in patient diagnosed as GDM at 24-28 week and at 36-38 weeks ( $r=-0.007, r=-$ 0.171 respectively) was statistically not significant.

Similarly, in control group the correlation of FMD with BMI at 24-28 weeks and at 34-36 weeks was $(r=-0.058$, $\mathrm{r}=-0.089$ respectively) statistically not significant, however in-patient with GDM the negative correlation of endothelial function with increased BMI was stronger as compared to control group.

Similarly, in a study by Anastasiou et al, a cross sectional study done in post-partum period where 52 subjects were recruited and divided into three groups, control $(n=19)$, non-obese GDM $(n=17)$ and obese GDM $(n=16)$. The subjects were studied at 3 to 7 months postpartum, when normoglycemia was restored in all.

FMD was significantly lower in the obese group as compared with controls (mean \pm SE: $1.6 \pm 2.5 \%$ and $10.3 \pm 4.4 \%$, respectively; $\mathrm{p}<0.001){ }^{23}$ Authors can conclude from our study and this study the importance of pre pregnancy and postpartum optimization of weight to decrease endothelial dysfunction and future risk of CVD.

In this study there was a negative correlation of FMD with HbA1c levels in both the groups but it was only significant in GDM patients. Similar results were also seen in a study done by Menon RS et al. ${ }^{23}$

As in this study the number of subjects recruited were less and follow up of the patients was done only for 6-12 weeks postpartum, more studies with a larger sample size and a longer follow up are required to correlate the impairment of endothelial function (assessed by FMD) and to assess the future cardiovascular risk in GDM patients.

\section{CONCLUSION}

This study revealed that when endothelial function as assessed by FMD was compared at different period of gestation (24-28 weeks, 36-38 weeks POG respectively) 
and at 6 weeks post-partum, the mean decrease in FMD at 36-38 weeks POG as compared to $24-28$ weeks POG and 6 week post-partum was statistically significant in patients with GDM and as well as in the healthy pregnant female, however this trend of change was same in both the groups and was not statistically significant when compared between the two group (GDM versus control).

There was a negative correlation of FMD with BMI (pre pregnancy) in both the groups with more-stronger correlation in the GDM group where mean BMI was $26.69 \mathrm{~kg} / \mathrm{m}^{2}$ indicating the important role of obesity specially in GDM patients (a modifiable risk factor) on endothelial function.

At 6-12 weeks post-partum the value of mean FMD was almost reverted back to 24-28 weeks POG value in both the groups and this reversal in the value of FMD was less in GDM group as compared to control group but this difference was statistically non-significant.

Endothelial function was affected more (decreased mean FMD) in GDM group as compared to controls in women with higher $\mathrm{HbA1c}$ value.

Funding: No funding sources

Conflict of interest: None declared

Ethical approval: The study was approved by the Institutional Ethics Committee

\section{REFERENCES}

1. American Diabetes Association. Diagnosis and classification of diabetes mellitus. Diabetes Care. 2011;34(Suppl 1):S62-9.

2. Seshiah V, Balaji V, Balaji MS, Sanjeevi CB, Green A. Gestational diabetes mellitus in India. J Assoc Physicians India. 2004;52:707-11.

3. Zargar AH, Sheikh MI, Bashir MI, Masoodi SR, Laway BA, Wani AI, et al. Prevalence of gestational diabetes mellitus in Kashmiri women from the Indian subcontinent. Diabetes Res Clin Pract. 2004;66:139-45.

4. Metzger BE, Lowe LP, Dyer AR, Trimble ER, Chaovarindr U, Coustan DR, et al. HAPO study cooperative research group, hyperglycemia and adverse pregnancy outcomes. N Engl J Med. 2008;358:19912002.

5. Bellamy L, Casas JP, Hingorani AD, Williams D. Type 2 diabetes mellitus after gestational diabetes: A systematic review and meta-analysis. Lancet. 2009;373:1773-9.

6. Shah BR, Retnakaran R, Booth GL. Increased risk of cardiovascular disease in young women following gestational diabetes mellitus. Diabetes Care. 2008;31:1668-9.

7. Retnakaran R, Shah BR. Mild glucose intolerance in pregnancy and risk of cardiovascular disease: a population-based cohort study. Canadian Med Asso J. 2009;181:371-6.
8. Sullivan SD, Umans JG, Ratner R. Gestational diabetes: implications for cardiovascular health. Current Diabetes Reports. 2012;12:43-52.

9. Retnakaran R. Glucose tolerance status in pregnancy: a window to the future risk of diabetes and cardiovascular disease in young women. Current Diab Rev. 2009;5:239-44.

10. Retnakaran R, Qi Y, Sermer M, Connelly PW, Hanley ATG, Zinman B. Glucose intolerance in pregnancy and future risk of pre-diabetes or diabetes. Diabetes Care. 2008;3:2026-31.

11. Retnakaran R, Qi Y, Connelly PW, Sermer M, Zinman B, Hanley AJ. Glucose intolerance in pregnancy and postpartum risk of metabolic syndrome in young women. J Clin Endocrinol Metab. 2010;95:670-7.

12. De Vriese S, Verbeuren TJ, de Voorde JV, Lameire Nh, Vanhoutte PM. Endothelial dysfunction in diabetes. Br J Pharmacol. 2000;130:963-74.

13. Celermajer DS, Sorensen KE, Gooch VM, Spiegelhalter DJ, Miller OI, Sullivan ID, et al. Non-invasive detection of endothelial dysfunction in children and adults at risk of atherosclerosis. Lancet. 1992;340:1111-5.

14. Lockhart CJ, Agnew CE, McCann A, Hamilton PK, Quinn CE, McCall DO, et al. Impaired flow-mediated dilatation response in uncomplicated Type 1 diabetes mellitus: influence of shear stress and microvascular reactivity. Clin Sci. 2011;121:129-39.

15. Celermajer DS, Sorensen KE, Bull C, Robinson J, Deanfield JE. Endothelium-dependent dilation in the systemic arteries of asymptomatic subjects relates to coronary risk factors and their interaction. J Am Coll Cardiol. 1994;24:1468-74.

16. Correctti MC, Anderson TJ, Benjamin EJ, Celermajer, D, Charbonneau E, Creager MA et al. Guideline for the ultrasound assessment of endothelial dependent flow mediated vasodilation of the brachialartery, A report of the brachial Artery Reactivity Task Force. J am coll Cardiol.2002;39:257-65.

17. Corretti MC, Anderson TJ, Benjamin EJ, Celermajer D, Charbonneau F, Creager MA, et al. Guidelines for the ultrasound assessment of endothelial dependent flow mediated vasodilation of the brachial artery a report of the brachial artery reactivity task force. J Am Coll Cardiol. 2002;39:257-65.

18. Jensen LA, Chik CL, Ryan EA. Review of gestational diabetes mellitus effects on vascular structure and function. Diabet Vasc Dis Res. 2016;13:170-82.

19. Garg P, Badhwar S, Jaryal AK, Kachhawa G, Deepak KK, Kriplani A. The temporal trend of vascular function in women with gestational diabetes. Vasc Med. 2017;22:96-102.

20. Paradisi G, Biaggi A, Ferrazzani S, De Carolis S, Caruso A. Abnormal carbohydrate metabolism during pregnancy: association with endothelial dysfunction. Diabetes Care. 2002;25:560-4.

21. Malhotra AS, Goel P, Chaudhary A, Kocchar S, Kaur G, Bhagat A. Serial profile of flow mediated dilatation in primigravida for prediction of preeclampsia and gestational hypertension. Hypert Preg. 2018;37:212-9.

22. Anastasiou E, Lekakis JP, Alevizaki M, Papamichael CM, Megas J, Souvatzoglou A, et al. Impaired endothelium dependent vasodilatation in women with 
previous gestational diabetes. Diab Care 1998;21:21115.

23. Guimaraes MF, Brandao AH, Rezende CA, Cabral AC, Brum AP, Leite HV, et al. Assessment of endothelial dysfunction in pregnant women with preeclampsia and gestational diabetes mellitus by flow mediated dilation of brachial artery. Arch Gynaecol Obstet. 2014;2900:441-7.
Cite this article as: Pandey N, Goel P, Malhotra A, Mehra R, Kaur N. Study of endothelial function in pregnant women with gestational diabetes mellitus by flow mediated dilation of brachial artery. Int $\mathbf{J}$ Reprod Contracept Obstet Gynecol 2020;9:2377-82. 